OPEN ACCESS

Edited by:

Michele Fornaro,

New York State Psychiatric Institute (NYSPI), United States

Reviewed by:

Giuseppe Tavormina, Independent Researcher, Provaglio d'Iseo, Italy

Chiara Fabbri,

King's College London,

United Kingdom

*Correspondence:

Carlo Antonio Bertellon

carlo.ab@hotmail.it

Specialty section:

This article was submitted to

Mood and Anxiety Disorders,

a section of the journal

Frontiers in Psychiatry

Received: 26 December 2020 Accepted: 02 March 2021

Published: 26 April 2021

Citation:

Carmassi C, Bertelloni CA, Cordone A, Dell'Oste V, Pedrinelli V. Barberi FM, Massimetti E, Bui E and Dell'Osso L (2021) Problematic Use of the Internet in Subjects With Bipolar

Disorder: Relationship With

Posttraumatic Stress Symptoms.

Front. Psychiatry 12:646385

doi: 10.3389/fpsyt.2021.646385

\section{Problematic Use of the Internet in Subjects With Bipolar Disorder: Relationship With Posttraumatic Stress Symptoms}

\author{
Claudia Carmassi ${ }^{1}$, Carlo Antonio Bertelloni ${ }^{1 *}$, Annalisa Cordone ${ }^{1}$, Valerio Dell'Oste ${ }^{1}$, \\ Virginia Pedrinelli ${ }^{1}$, Filippo Maria Barberi ${ }^{1}$, Enrico Massimetti ${ }^{1}$, Eric Bui ${ }^{2}$ and \\ Lliliana Dell'Osso ${ }^{1}$ \\ ${ }^{1}$ Department of Clinical and Experimental Medicine, University of Pisa, Pisa, Italy, ${ }^{2}$ Caen University Hospital, University of \\ Caen Normandy, Caen, France
}

Background: Literature shows a high risk for problematic use of the Internet (PUI) in mood disorders, especially in bipolar disorder (BD). In subjects with $\mathrm{BD}$, traumatic events and posttraumatic stress disorder (PTSD) are related to alcohol or substance use disorder, as well as to gambling disorder. However, little is known about the possible association between traumatic exposure and PUI. The present study was aimed at examining the relationship between PUI and trauma exposure, besides PTSD symptoms, in subjects with $\mathrm{BD}$.

Methods: A sample of 113 subjects with BD was screened to putative PUI. Furthermore, they completed the Trauma and Loss Spectrum Self-Report (TALS-SR) to assess traumatic events and posttraumatic stress symptoms.

Results: Twenty-four subjects (21.2\%) reported putative PUI. Subjects with putative PUI presented significantly higher scores in the TALS-SR domains Potentially Traumatic Events, Re-experiencing, Maladaptive coping, and Arousal, as well as in the TALS-SR total score. In a logistic regression model, a positive association emerged between Potentially Traumatic Events and Arousal TALS-SR domains and putative PUI.

Conclusion: One in five patients with BD screened positive for PUI. A significant association between PUI and lifetime traumatic events as well as PTSD symptoms emerged, highlighting the relevance of the comorbidity between PTSD and PUI in subjects with $\mathrm{BD}$.

Keywords: problematic use of the internet, internet addiction, behavioral addiction, bipolar disorder, trauma, PTSD, arousal, TALS-SR

\section{INTRODUCTION}

Internet use has become common in Western countries and is now present in a substantial part of everyday life (1). The rapid growth of its use during the last decades provided a new environment in which new maladaptive behaviors have progressively emerged (2). It is in fact now recognized the existence of a spectrum of Internet usage, from a controlled and adaptive behavior to an uncontrolled and maladaptive one (3). The expression "Problematic use of the Internet" (PUI) 
(4) was conceptualized in order to encompass previous different but substantially overlapping conditions, like Problematic Internet Use, Internet Addiction, or Compulsive Internet use (57). It includes a range of "potentially problematic Internet-related behaviors," including those related to gaming, gambling, buying, pornography viewing, social networking, "cyber-bullying," and "cyberchondria," among others (4). PUI was included among the so-called behavioral addictions (8), and it may result in serious psychological, economic, social, school, and working difficulties, leading to functioning impairment $(3,9)$.

Although growing evidence suggests that PUI is associated with Major Depressive Disorder or depressive symptoms (1013), the relationship with other mood disorder, particularly bipolar disorder (BD) has been explored to a lesser extent (14). Literature reported an overlap, in neurobiological characteristics, clinical features, and prevalence rates between PUI and BD (15), particularly mania and hypomania. Some authors then proposed to define these two latter conditions as exclusion criteria for Internet-related pathologies, as for other behavioral addictions (16-19). During elevated mood episodes, in fact, increased tendency to PUI may be related to arousal, restlessness, and enhanced excitement or may be a manifestation of an inclination for reward-based behaviors. Conversely, others have suggested that PUI, as well as other behavioral addictions may represent a self-medication strategy for bipolar individuals, to cope with anxiety, tension, and other negative emotions of depressive episodes (20).

Despite other behavioral addictions including gambling disorder, compulsive buying, or sex addiction, are commonly reported in individuals with BD (20-22), scant and still inconclusive data are available on the PUI. On the other hand, some studies reported $\mathrm{BD}$ rates among individuals with PUI ranging between $13 \%$ and $55 \%(14,18,19)$. Surveys on adolescents and university students corroborated these previous data on the relationship between PUI and BD $(23,24)$. However, a recent large study, performed on a cohort of 6,510 Korean subjects, did not find significant differences in the rate of BD in individuals with PUI with respect to those without it (25).

Conversely, to the best of our knowledge, only two studies explored PUI rates in $\mathrm{BD}$ patients, reporting similar or lower levels with respect to healthy controls $(26,27)$. In this regard, it is important to notice that Di Nicola et al. (26) explored PUI rates among patients enrolled until 2008, and Internet usage pattern and PUI conceptualization as an addiction evolved since then; furthermore, Sapir et al. (27) in their study compared a group of bipolar disorder I (BDI) 50 subjects with a healthy control group differing for social or socioeconomic status, pointing out as this variance could influence PUI and other behavioral addiction rates. Thus, the need to examine PUI in bipolar samples remains relevant.

A relationship has been consistently reported between traumatic experiences, posttraumatic stress disorder (PTSD) and addictive behaviors including substance or alcohol use disorders (28-31) and gambling disorder (32). This propensity to addiction in traumatized individuals could represent a maladaptive "self-medication" coping mechanism in order to reduce the hyperarousal component of PTSD $(33,34)$. Some authors have also suggested that arousal associated with withdrawal may be augmented by PTSD-linked hyperarousal, making the addictive behavior interruption even more difficult (35). The existence of an association between PTSD and gambling is demonstrated by several studies reporting a range of esteemed rates of PTSD between $12.5 \%$ and $34 \%$ in samples of treatment-seeking gamblers (36-39). It may be hypothesized that the same pattern of association could be observed for other behavioral addictions such as PUI. Most recently, in fact, few but suggestive studies pointed out the relationship between traumatic experiences or stressful life events and PTSD on PUI. Some recent data highlighted an association between a history of emotional or sexual trauma or stressful life events and PUI among adolescent and young adults (40-43). A recent large study conducted on a sample of South Korean students survived to a shipwreck showed that PUI was strongly related to PTSD development (44). Furthermore, posttraumatic stress symptomatology in BD was related to addictive disorders such as alcohol or substance use and, consequently, to a worse outcome (45).

Upon this evidence, we may speculate that a behavioral addiction like PUI may also be related to traumatic exposure and PTSD burden in BD patients, but no data are yet available on this association. The present study aims to explore the impact of posttraumatic stress symptoms on PUI among hospitalized patients with BD.

\section{METHODS}

\section{Participants and Procedures}

A consecutive sample of 133 in-patients hospitalized in a major Italian psychiatric clinic aged 18-60 years with a diagnosis of bipolar I or bipolar II disorder were recruited. From the initial sample, $n=113(85 \%)$ subjects had usable (nonmissing) data for the present study. The enrollment was conducted from November 2016 to December 2018, framed in the "Italian multicenter study for the validation of the Adult Autism Subthreshold Spectrum questionnaire" (Protocol number $551 / 2015)$. Inability to understand Italian language or other restrictions in verbal communication was an exclusion criterion. All eligible subjects were informed on study procedures, had opportunity to ask questions, and were asked to provide written informed consent.

\section{Measures}

We used the Structured Clinical Interview for DSM-5 Disorders (SCID-5) (46) to assess BD diagnosis. Furthermore, according to a previous study (5), we utilized the following one-item question to screen putative PUI in the sample: "Do you spend a lot of time playing videogames or surfing on internet, to the extent of forgetting to do routine tasks?." The item was extrapolated from the Adult Autism Subthreshold Spectrum (AdAS) (47), a questionnaire developed and validated as part of a multicenter study to assess the presence of the wide spectrum of manifestations associated with autism spectrum disorder. Specifically, in the present study, a positive endorsement of the mentioned item indicated putative PUI. 
The Trauma and Loss Spectrum Self Report (TALS-SR) is an instrument developed for the assessment of post-traumatic stress symptoms (48-50). It includes 116 items exploring the lifetime experience of a range of losses and/or traumatic events and lifetime symptoms, behaviors, and personal characteristics that might represent manifestations and/or risk factors for the development of a stress-response syndrome. The instrument is organized into nine domains including the following: loss events (I); grief reactions (II); potentially traumatic events (III); reactions to losses or upsetting events (IV); re-experiencing (V); avoidance and numbing (VI); maladaptive coping (VII); arousal (VIII); and personal characteristics/risk factors (IX). The responses to the items are coded in a dichotomous way (yes/no), and domain scores are obtained by counting the number of positive answers. The correlation between the self-report (TALS-SR) and the interview format (SCI-TALS) of the TALS always exceeded the threshold of 0.90 , defining a substantial reliability in all the domains (49).

\section{Statistical Analyses}

Chi-square test (or Fisher's test if appropriate) and Student's $t$ tests were used to compare sociodemographic and clinical characteristics, as well as TALS-SR domains between individuals with and without PUI. Furthermore, a logistic regression analysis was performed to examine the association of TALS-SR domains (as independent variables) with the presence of putative PUI (as the dependent variable), after controlling for the effects of potentially confounding variables age and gender. In order to examine whether arousal mediated the association between traumatic exposure and PUI, two logistic regression models were conducted, as follows: the first for subjects with low arousal symptoms (TALS-SR arousal domain under the median of the total sample 2); the second for subjects with high arousal symptoms (TALS-SR arousal domain over the median of the total sample 2). Chi-square test (or Fisher's test if appropriate) was computed to compare the endorsement rates of the items of the TALS-SR arousal domain (VIII) between subjects with PUI and without ones. The statistical analyses were carried out using SPSS version 25.0. The level of statistical significance was set to $p<$ 0.05 (two-tailed).

\section{RESULTS}

In the study sample, the mean age was $43.0 \pm 12.5$ years, and 72 participants (63.7\%) were males. Twenty-seven subjects (25.5\%) had college degree, the majority was employed $(n=64,59.8 \%)$, and $42(39.6 \%)$ subjects were married. Furthermore, 85 (80.2\%) patients had a positive family psychiatric history, bipolar disorder I (BDI) was diagnosed in $73(67.0 \%)$ patients while bipolar disorder II (BDII) in 36 of them (33.0\%). Participants were almost equally divided in depressive $(55,48.7 \%)$ and manic/hypomanic episode polarity at the time of the hospital admission $(58,51.3 \%)$.

In the total sample, $24(21.2 \%)$ subjects reported putative PUI. No significant differences emerged in sociodemographic and clinical characteristic between BD subjects with and without PUI, except for age which was about 10 years lower among the former $(34.46 \pm 12.93$ vs. $44.93 \pm 11.57, p<0.001)$ (see Table 1 ).
Subjects with PUI reported significantly higher mean scores in the TALS-SR domains potentially traumatic events (III), Reexperiencing (IV), Maladaptive coping (VII), and Arousal (VIII) and the TALS-SR total score, compared with no-PUI ones (Table 2).

In the logistic regression on the total sample, the TALS-SR Domains Potentially traumatic events (III) $[b=0.21$ (SE $=0.097$ ), $p=0.027]$, Arousal (VIII) $[b=0.58$ (SE $=0.264), p=0.027]$, and Personal characteristics/risk factors (IX) $[b=-0.51$ (SE $=0.228)$, $p=0.024$ ] were associated with the PUI (see Table 3).

We conducted two logistic regression analyses to assess the possible relationship between the TALS-SR Domain exposure to traumatic event (III) as an independent variable and the putative PUI as the dependent variable. The first regression was performed in the subjects with low arousal symptoms and was not significant $[b=-0.18$ (SE $=$ 0.14), $p=0.982$ ] (see Table 4A). Conversely, the regression conducted in subjects with high arousal symptoms, showed a significant association between exposure to traumatic event (III) and PUI $[b=0.27$ (SE $=0.09$ ), $p=0.002]$ (see Table 4B). This result pointed out a possible mediation effect of arousal on the association between traumatic exposure and PUI.

Finally, subjects with PUI presented a significantly higher endorsement rates of TALS-SR arousal domain items $n=105$ (... have trouble concentrating or paying attention, for example, following the story line of a TV program or book or remembering what you had read?) and $n=106$ (... feel like you just couldn't relax or let your guard down?) (see Table 5).

\section{DISCUSSION}

To the best of our knowledge, this is the first study exploring the associations between PUI and posttraumatic stress symptoms among subjects with $\mathrm{BD}$. In particular, we found putative PUI in one in five subjects. Individuals with $\mathrm{BD}$ and PUI reported significantly more lifetime traumatic events with respect to no-PUI ones, as well as higher levels of posttraumatic stress symptoms.

The rates of PUI reported in the present study are in line with previous studies describing high rates of both drugrelated and behavioral addictions in $\mathrm{BD}$ (20), despite appearing to be slightly higher than those specifically reporting PUI rates. Methodological differences may render comparison difficult $(26,27)$ corroborating the fact that the relationship between PUI and mood disorders has resulted to be complex (15) and the comorbidity rates are still object of arguing. However, our results corroborate a recent large meta-analysis concluded underlining the need to undertake systematic and routine screening and comprehensive assessment of possible co-occurring behavioral addictions, including PUI, among patients with $\mathrm{BD}$. In particular, the authors addressed the potential negative impact that these disorders may have directly on the bipolar illness and, more in general, to the impairment in the social, relational, and economic quality of life (20). In light of these evidence, exploring the 
TABLE 1 | Sociodemographic and clinical characteristics in BD subjects with $(N=$ 24) and without PUI ones $(N=89)$.

\begin{tabular}{|c|c|c|c|}
\hline & PUI & No-PUI & $p$ \\
\hline & $N(\%)$ & $N(\%)$ & \\
\hline \multicolumn{4}{|l|}{ Gender } \\
\hline Male & 19 (79.2) & 53 (59.6) & 0.125 \\
\hline Female & $5(20.8)$ & $36(40.4)$ & \\
\hline \multicolumn{4}{|l|}{ Education } \\
\hline Not graduated & $18(85.7)$ & $61(71.8)$ & 0.301 \\
\hline Graduated & $3(14.3)$ & $24(28.2)$ & \\
\hline Missing data & 3 & 4 & \\
\hline \multicolumn{4}{|l|}{ Occupation } \\
\hline Unemployed & $12(54.5)$ & $31(36.5)$ & 0.194 \\
\hline Employed & $10(45.5)$ & $54(63.5)$ & \\
\hline Missing data & 2 & 4 & \\
\hline \multicolumn{4}{|l|}{ Marital status } \\
\hline Single/divorced/widowed & $15(71.4)$ & $49(57.7)$ & 0.364 \\
\hline Married & $6(28.6)$ & $36(42.3)$ & \\
\hline Missing data & 3 & 4 & \\
\hline \multicolumn{4}{|l|}{ Psychiatric family history } \\
\hline Negative & 7 (33.3) & $14(16.5)$ & 0.080 \\
\hline Positive & $14(66.7)$ & $71(83.5)$ & \\
\hline Missing data & 3 & 4 & \\
\hline \multicolumn{4}{|l|}{ Type of bipolar disorder } \\
\hline BD-I & $18(75.0)$ & $55(64.7)$ & 0.245 \\
\hline BD-II & $6(25.0)$ & 30 (35.3) & \\
\hline Missing data & & 4 & \\
\hline \multicolumn{4}{|l|}{ Current episode polarity } \\
\hline Depressive & $9(37.5)$ & $46(51.7)$ & 0.158 \\
\hline \multirow[t]{2}{*}{ Manic/Hypomanic } & $15(62.5)$ & $43(48.3)$ & \\
\hline & Mean \pm SD & Mean \pm SD & $p$ \\
\hline Age (years) & $34.46 \pm 12.93$ & $45.03 \pm 11.59$ & $<0.001$ \\
\hline
\end{tabular}

TABLE 2 | Comparison of TALS-SR domains and total score between BD subjects with $(N=24)$ and without PUI $(N=89)$.

\begin{tabular}{lrrr}
\hline & $\begin{array}{c}\text { PUI } \\
\text { (mean } \pm \text { SD) }\end{array}$ & $\begin{array}{c}\text { No-PUI } \\
\text { (mean } \pm \text { SD) }\end{array}$ & $\boldsymbol{p}$ \\
\hline (I) Loss events & $4.83 \pm 2.01$ & $4.84 \pm 2.09$ & 0.807 \\
(II) Grief reactions & $15.67 \pm 5.61$ & $12.90 \pm 5.96$ & 0.072 \\
(III) Potentially traumatic events & $8.21 \pm 5.31$ & $4.86 \pm 3.26$ & 0.004 \\
(IV) Reactions to losses or & $9.25 \pm 4.19$ & $8.17 \pm 4.06$ & 0.312 \\
upsetting events & & & \\
(V) Re-experiencing & $5.17 \pm 2.65$ & $4.02 \pm 2.29$ & 0.042 \\
(VI) Avoidance and numbing & $6.45 \pm 2.75$ & $4.88 \pm 2.99$ & 0.024 \\
(VII) Maladaptive coping & $3.12 \pm 2.49$ & $2.02 \pm 1.90$ & 0.050 \\
(VIII) Arousal & $3.33 \pm 1.63$ & $2.25 \pm 1.62$ & 0.006 \\
(IX) Personal characteristics/risk & $2.50 \pm 1.53$ & $2.61 \pm 1.65$ & 0.957 \\
factors & & & \\
Total TALS-SR score & $58.54 \pm 22.32$ & $46.57 \pm 17.63$ & 0.034 \\
\hline
\end{tabular}

determinant of these comorbidity appears to be a critical issue for researchers, in order to develop specific prevention or treatment strategies.
TABLE 3 | Logistic regression analysis: age, gender, and TALS-SR domains as predictive factors associated with PUI in the total sample $(N=113)$.

\begin{tabular}{lcccc}
\hline Predictive factors & $\boldsymbol{B}$ (S.E.) & $\mathbf{O . R .}$ & $\mathbf{9 5 \%} \mathbf{C l}$ & $\boldsymbol{p}$ \\
\hline (I) Loss events & $-0.31(0.198)$ & 0.73 & $0.50-1.08$ & 0.117 \\
(II) Grief reactions & $0.12(0.069)$ & 1.13 & $0.98-1.29$ & 0.082 \\
$\begin{array}{l}\text { (III) Potentially traumatic } \\
\text { events }\end{array}$ & $0.21(0.097)$ & 1.24 & $1.02-1.50$ & 0.027 \\
(IV) Reactions to losses or & $-0.05(0.110)$ & 0.94 & $0.76-1.17$ & 0.604 \\
upsetting events & & & & \\
(V) Re-experiencing & $0.04(0.181)$ & 1.04 & $0.73-1.49$ & 0.811 \\
(VI) Avoidance and numbing & $0.04(0.143)$ & 1.04 & $0.79-1.34$ & 0.780 \\
(VII) Maladaptive coping & $-0.23(0.210)$ & 0.80 & $0.53-1.20$ & 0.273 \\
(VIII) Arousal & $0.58(0.264)$ & 1.80 & $1.07-3.00$ & 0.027 \\
(IX) Personal & $-0.51(0.228)$ & 0.60 & $0.38-0.93$ & 0.024 \\
characteristics/risk factors & & & & \\
K & $1.15(1.540)$ & 3.14 & - & 0.457 \\
\hline
\end{tabular}

Cox $R^{2}=0.286 ;$ Nagelkerke $R^{2}=0.444$.

Hosmer-Lemeshow test: $\chi^{2}=6.843, p=0.554$.

Global-goodness-fit percentage $=83.2 \%$.

TABLE 4A | Logistic regression analysis: TALS-SR Domain III (potentially traumatic events) as predictive factor associated with PUI in BD patients with low arousal symptoms.

\begin{tabular}{lcccc}
\hline Predictive factors & $\boldsymbol{B}$ (S.E.) & O.R. & $\mathbf{9 5 \%} \mathbf{C l}$ & $\boldsymbol{p}$ \\
\hline (III) Potentially traumatic events & $-0.18(0.14)$ & 0.98 & $0.75-1.28$ & 0.982 \\
\hline
\end{tabular}

Cox $R^{2}<0.001$; Nagelkerke $R^{2}=0.001$.

Hosmer-Lemeshow test: $\chi^{2}=3.664, p=0.722$.

Global-goodness-fit percentage $=85.7 \%$.

TABLE 4B | Logistic regression analysis: TALS-SR Domain III (potentially traumatic events) as predictive factor associated with PUI in BD patients with high arousal symptoms.

\begin{tabular}{lcccc}
\hline Predictive factors & B (S.E.) & O.R. & $\mathbf{9 5 \%} \mathbf{C l}$ & $\boldsymbol{p}$ \\
\hline (III) Potentially traumatic events & $0.274(0.09)$ & 1.31 & $1.10-1.56$ & 0.002 \\
\hline
\end{tabular}

Cox $R^{2}=0.201$; Nagelkerke $R^{2}=0.290$.

Hosmer-Lemeshow test: $\chi^{2}=7.261, p=0.402$.

Global-goodness-fit percentage $=77.2 \%$.

The present study first shed light on the role of traumatic events and the prevalence of PTSD symptoms in BD patients. This is a particularly promising research pathway, as suggested by the results of the few studies that have been focusing on PUI in PTSD (44). Literature, in fact, showed a relationship between a history of stressful events or sexual abuse and PUI among adolescents and young adults (40-43) and an increased risk of PTSD development among adolescents with PUI (25). While research on this issue is to date at its preliminary stage, the association between PTSD and other addiction disorders such as substance or alcohol use disorder and gambling disorder, are widely acknowledged $(32,51,52)$. Furthermore, several studies 
TABLE 5 | TALS-SR arousal domain (VIII) item endorsement rates between BD subjects with $(N=24)$ and without PUI ones $(N=89)$.

\begin{tabular}{|c|c|c|c|}
\hline & $\begin{array}{c}\text { PUI } \\
N(\%)\end{array}$ & $\begin{array}{l}\text { No-PUI } \\
N(\%)\end{array}$ & $p$ \\
\hline 105)... have trouble concentrating or paying attention? & $21(87.5 \%)$ & $54(60.7 \%)$ & 0.026 \\
\hline 106)... feel like you just couldn't relax or let your guard down? & $19(79.25 \%)$ & $42(47.2 \%)$ & 0.011 \\
\hline $\begin{array}{l}\text { 107)... startle easily at the sound of sudden noises, or when someone touched you, spoke to you, or } \\
\text { approached you unexpectedly? }\end{array}$ & $14(58.3 \%)$ & 35 (39.3\%) & 0.151 \\
\hline
\end{tabular}

highlighted how PTSD negatively affects the course of BD (53$57)$ and increases the risk of drug-related addictions $(45,58)$. We add to the literature that also PUI, as alcohol, substance, and gambling, is related to posttraumatic stress symptoms in bipolar patients. These data also suggest a detrimental role for PTSD hyperarousal symptoms, especially attention deficit and startle, on PUI like that previously reported for alcohol or substance use. In this regard, some authors reported how hyperarousal is the most prominent symptom cluster in determining PTSD severity over time (59). Furthermore, in several studies, hyperarousal symptoms were specifically associated with substance abuse among subjects with PTSD (60-63). Recently, Green et al. showed a relationship between arousal levels and gambling disorder, suggesting a role for hyperarousal in non-substancerelated addictive disorders (34). The results of the present study pointed out the relevant role of arousal in bipolar patients with PUI, corroborating previous studies and suggesting that these symptoms may have a significant role in PUI comorbidity too. Interestingly, risk factors for PTSD, such as impulsivity or being sensitive to loss, were negatively related to PUI. It is in contrast with previous studies showing an association between impulsivity and PUI $(64,65)$. This difference may be due to our sample characteristics. We may speculate that in traumatized subjects with $\mathrm{BD}$, these personal features could be related to other kinds of maladaptive behaviors or other addictions.

In our study, the temporal relationship between PUI and posttraumatic stress symptoms remains unclear. On one hand, we may speculate that bipolar patients who experienced a traumatic event tend to use the Internet excessively in order to cope with negative emotions and anxious states linked to posttraumatic stress symptoms. On the other hand, subjects reporting PUI may be more vulnerable to stressful events or more prone to develop PTSD. Given that a causal link cannot be obtained by our results, previous studies, in accordance with the former hypothesis, showed an association between childhood trauma experience and PUI, highlighting the possible role of PUI as a maladaptive coping method to traumatic events and distressful memories (40, 43).

Despite our interesting results, some limitations should be acknowledged. The most important one is the assessment of PUI using an item from the AdAS Spectrum questionnaire that may not be specific enough, and future studies will need to use diagnostic interviews. A second limitation is the relatively small sample size. The third limitation is the lack of assessment of other psychiatric comorbidities, such as anxiety, which might have been potential confounds. Another limitation is the crosssectional design of the study and the lack of information on the onset and the duration of the PUI and the PTSD. Furthermore, the assessments were performed during an acute phase of the $\mathrm{BD}$, and this may have affected the results. Finally, PTSD symptoms were assessed with a self-report scale. However, the self-report version of the TALS had previously demonstrated good psychometric properties and a high correlation with the clinician-rated version.

In conclusion, we found that putative PUI is quite common in subjects with BD and is associated with history of traumatic events as well as posttraumatic stress symptoms. Particularly, in a logistic regression model, hyperarousal and a history of potentially traumatic events predicted the presence of putative PUI, highlighting their role in patients with PUI. We may argue that in light of these results, systematical use of trauma-focused therapeutic approaches, such as cognitive behavioral therapy or prolonged exposure therapy, should be even more encouraged. These psychotherapies, in fact, may not only improve patient's posttraumatic stress symptoms in mood disorders (66-68) but also reduce the risk of developing behavioral addiction disorders such as PUI. Future longitudinal research is warranted to better understand the link between posttraumatic stress symptoms and PUI in BD. This could lead to an improvement in the development of tailored assessment and interventions of patients with BD.

\section{DATA AVAILABILITY STATEMENT}

The datasets generated for this article are not readily available because, the data supporting the findings of the article are not publicly available, but it can be provided by the corresponding author on reasonable request. Requests to access the datasets should be directed to Dr. Carlo Antonio Bertelloni carlo.ab@hotmail.it.

\section{ETHICS STATEMENT}

The studies involving human participants were reviewed and approved by Comitato Etico Regionale per la Sperimentazione Clinica della Regione Toscana AREA VASTA NORD OVEST (CEAVNO, Pisa, Italy). The patients/participants provided their written informed consent to participate in this study. 


\section{AUTHOR CONTRIBUTIONS}

All authors gave substantial contribution to the study and approved the final version of the manuscript and the manuscript submission to Frontiers in Psychiatry.

\section{REFERENCES}

1. Anderson EL, Steen E, Stavropoulos V. Internet use and problematic internet use: a systematic review of longitudinal research trends in adolescence and emergent adulthood. Int J Adolesc Youth. (2016) 22:430-54. doi: $10.1080 / 02673843.2016 .1227716$

2. World Health Organization. Public Health Implications of Excessive Use of the Internet, Computers, Smartphones and Similar Electronic Devices: Meeting Report, Main Meeting Hall, Foundation for Promotion of Cancer Research, National Cancer Research Centre, Tokyo, Japan, 27-29 August 2014. World Health Organization (2015). Available online at: https://apps.who.int/iris/ handle/10665/184264

3. Billieux J, King DL, Higuchi S, Achab S, Bowden-Jones H, Hao W, et al. Functional impairment matters in the screening and diagnosis of gaming disorder. J Behav Addict. (2017) 6:285-9. doi: 10.1556/2006.6.2017.036

4. Fineberg NA, Demetrovics Z, Stein DJ, Ioannidis K, Potenza MN, Grünblatt E, et al. Manifesto for a European research network into Problematic Usage of the Internet. Eur Neuropsychopharmacol. (2018) 28:1232-46. doi: 10.1016/j.euroneuro.2018.08.004

5. Dell'Osso L, Bertelloni CA, Di Paolo M, Avella MT, Carpita B, Gori F, et al. Problematic internet use in university students attending three superior graduate schools in italy: is autism spectrum related to suicide risk? Int J Environ Res Public Health. (2019) 16:1098. doi: 10.3390/ijerph16071098

6. Weinstein A, Lejoyeux M. Internet addiction or excessive internet use. Am J Drug Alcohol Abuse. (2010) 36:277-83. doi: 10.3109/00952990.2010.491880

7. Mihajlov M, Vejmelka L. Internet addiction: a review of the first twenty years. Psychiatr Danubina. (2017) 29:260-72. doi: 10.24869/psyd.2017.260

8. Chamberlain SR, Lochner C, Stein DJ, Goudriaan AE, van Holst RJ, Zohar J, et al. Behavioural addiction-A rising tide? Eur Neuropsychopharmacol. (2016) 26:841-55. doi: 10.1016/j.euroneuro.2015.08.013

9. Beard KW, Wolf EM. Modification in the proposed diagnostic criteria for Internet Addiction. Cyberpsychol Behav. (2001) 4:377-83. doi: 10.1089/109493101300210286

10. Carli V, Durkee T, Wasserman D, Hadlaczky G, Despalins R, Kramarz E, et al. The association between pathological internet use and comorbid psychopathology: a systematic review. Psychopathology. (2013) 46:1-13. doi: $10.1159 / 000337971$

11. Starcevic V, Khazaal Y. Relationships between behavioural addictions and psychiatric disorders: what is known and what is yet to be learned? Front Psychiatry. (2017) 8:53. doi: 10.3389/fpsyt.2017.00053

12. Chi X, Liu X, Guo T, Wu M, Chen X. Internet addiction and depression in chinese adolescents: a moderated mediation model. Front Psychiatry. (2019) 10:816. doi: 10.3389/fpsyt.2019.00816

13. Destoop M, Morrens M, Coppens V, Dom G. Addiction, anhedonia, and comorbid mood disorder. a narrative review. Front Psychiatry. (2019) 10:311. doi: $10.3389 /$ fpsyt.2019.00311

14. Bernardi S, Pallanti S. Internet addiction: a descriptive clinical study focusing on comorbidities and dissociative symptoms. Compr Psychiatry. (2009) 50:510-6. doi: 10.1016/j.comppsych.2008.11.011

15. Caldiroli A, Serati M, Buoli M. Is internet addiction a clinical symptom or a psychiatric disorder? A comparison with bipolar disorder. J Nerv Ment Dis. (2018) 206:644-56. doi: 10.1097/NMD.0000000000000861

16. Ko CH, Yen JY, Chen CC, Chen SH, Yen CF. Proposed diagnostic criteria of Internet addiction for adolescents. J Nerv Ment Dis. (2005) 193:728-33. doi: 10.1097/01.nmd.0000185891.13719.54

17. Ko CH, Yen JY, Chen SH, Wang PW, Chen CS, Yen CF. Evaluation of the diagnostic criteria of Internet gaming disorder in the DSM5 among young adults in Taiwan. J Psychiatr Res. (2014) 53:103-10. doi: $10.1016 /$ j.jpsychires.2014.02.008

\section{FUNDING}

The University funding of the University of Pisa supported the present study; no other economic source was interested.
18. Shapira NA, Goldsmith TD, Keck PE Jr., Khosla UM, McElroy SL. Psychiatric features of individuals with problematic internet use. J Affect Disord. (2000) 57:267-72. doi: 10.1016/S0165-0327(99)00107-X

19. Wölfling KL, Beutel ME, Dreier M, Müller KW. Bipolar spectrum disorders in a clinical sample of patients with Internet addiction: hidden comorbidity or differential diagnosis? J Behav Addict. (2015) 4:101-5. doi: 10.1556/2006.4.2015.011

20. Varo C, Murru A, Salagre E, Jiménez E, Solé B, Montejo $\mathrm{L}$, et al. Behavioral addictions in bipolar disorders: a systematic review. Eur Neuropsychopharmacol. (2019) 29:76-97. doi: 10.1016/j.euroneuro.2018.10.012

21. Lister JJ, Milosevic A, Ledgerwood DM. Psychological characteristics of problem gamblers with and without mood disorder. Can J Psychiatry. (2015) 60:369-76. doi: 10.1177/070674371506000806

22. Petry NM, Stinson FS, Grant BF. Comorbidity of DSM-IV pathological gambling and other psychiatric disorders: results from the national epidemiologic survey on alcohol and related conditions. J Clin Psychiatry. (2005) 66:564-74. doi: 10.4088/JCP.v66n0504

23. Park S, Hong KE, Park EJ, Ha KS, Yoo HJ. The Association between problematic internet use and depression, suicidal ideation and bipolar disorder symptoms in Korean adolescents. Aust N Z J Psychiatry. (2013) 47:153-9. doi: 10.1177/0004867412463613

24. Tang CS, Koh YY. Online social networking addiction among college students in Singapore: Comorbidity with behavioral addiction and affective disorder. Asian J Psychiatr. (2017) 25:175-8. doi: 10.1016/j.ajp.2016.10.027

25. Kim BS, Chang SM, Park JE, Seong SJ, Won SH, Cho MJ. Prevalence, correlates, psychiatric comorbidities, and suicidality in a community population with problematic Internet use. Psychiatry Res. (2016) 244:249-56. doi: 10.1016/j.psychres.2016.07.009

26. Nicola Di M, Tedeschi D, Mazza M, Martinotti G, Harnic D, Catalano $\mathrm{V}$, et al. Behavioural addictions in bipolar disorder patients: role of impulsivity and personality dimensions. J Affect Disord. (2010) 125:82-8. doi: 10.1016/j.jad.2009.12.016

27. Sapir R, Zohr AH, Bersudsky Y, Belmaker RH, Osher Y. Behavioral addiction in euthymic patients with bipolar I disorder: a comparison to controls. Int J Bipolar Disord. (2013) 1:27. doi: 10.1186/2194-7511-1-27

28. Back SE, Killeen TK, Teer AP, Hartwell EE, Federline A, Beylotte F, et al. Substance use disorder and PTSD: an exploratory study of treatment preferences among military veterans. Addict Behav. (2014) 39:369-73. doi: 10.1016/j.addbeh.2013.09.017

29. Carmassi C, Stratta P, Massimetti G, Bertelloni CA, Conversano C, Cremone IM, et al. New DSM-5 maladaptive symptoms in PTSD: gender differences and correlations with mood spectrum symptoms in a sample of high school students following survival of an earthquake. Ann Gen Psychiatry. (2014) 13:28. doi: 10.1186/s12991-014-0028-9

30. Simmons S, Sùarez L. Substance abuse and trauma. Child Adolesc Psych Clin N Am. (2016) 25:723-34. doi: 10.1016/j.chc.2016.05.006

31. Basedow LA, Kuitunen-Paul S, Roessner V, Golub Y. Traumatic events and substance use disorders in adolescents. Front Psychiatry. (2020) 11:559. doi: $10.3389 /$ fpsyt.2020.00559

32. Najavits LM, Meyer T, Johnson KM, Korn D. Pathological gambling and posttraumatic stress disorder: a study of the co-morbidity versus each alone. $J$ Gambl Stud. (2011) 27:663-83. doi: 10.1007/s10899-010-9230-0

33. Allen JP, Crawford EF, Kudler H. Nature and treatment of comorbid alcohol problems and post traumatic stress disorder among American military personnel and veterans. Alcohol Res. (2016) 38:133-40.

34. Green CL, Nahhas RW, Scoglio AA, Elamn I. Post-traumatic stress symptoms in pathological gambling: potential evidence of anti-reward processes. J Behav Addict. (2017) 6:98-101. doi: 10.1556/2006.6.2017.006 
35. Jacobson IG, Ryan MA, Hooper TI, Smith TC, Amoroso PJ, Boyko EJ, et al. Alcohol use and alcohol-related problems before and after military combat deployment. JAMA. (2008) 300:663-75. doi: 10.1001/jama.300.6.663

36. Taber JI, McCormick RA, Ramirez LF. The prevalence and impact of major life stressors among pathological gamblers. Int J the Addict. (1987) 22:71-9. doi: 10.3109/10826088709027414

37. McCormick RA, Taber JI, Kruedelbach N. The relationship between attributional style and post-traumatic stress disorder in addicted patients. $J$ Trauma Stress. (1989) 2:477-87. doi: 10.1002/jts.2490020410

38. Specker SM, Carlson GA, Edmonson KM, Johnson PE, Marcotte M. Psychopathology in pathological gamblers seeking treatment. J Gambl Stud. (1996) 12:67-81. doi: 10.1007/BF01533190

39. Ledgerwood DM, Petry NM. Posttraumatic stress disorder symptoms in treatment seeking pathological gamblers. J Trauma Stress. (2006) 19:411-6. doi: $10.1002 /$ jts.20123

40. Schimmenti A, Passanisi A, Caretti V, La M.arca L, Granieri A, Iacolino C, et al. Traumatic experiences, alexithymia, and Internet addiction symptoms among late adolescents: a moderated mediation analysis. Addict Behav. (2015) 64:314-20. doi: 10.1016/j.addbeh.2015.11.002

41. Tang J, Yu Y, Du Y, Ma Y, Zhang D, Wang J. Prevalence of internet addiction and its association with stressful life events and psychological symptoms among adolescent internet users. Addict Behav. (2014) 39:744-7. doi: 10.1016/j.addbeh.2013.12.010

42. Kircaburun K, Griffiths MD, Billieux J. Psychosocial factors mediating the relationship between childhood emotional trauma and internet gaming disorder: a pilot study. Eur J Psychotraumatol. (2019) 10:1565031. doi: 10.1080/20008198.2018.1565031

43. Bussone S, Trentini C, Tambelli R, Carola V. Early-life interpersonal and affective risk factors for pathological gaming. Front Psychiatry. (2020) 11:423. doi: 10.3389/fpsyt.2020.00423

44. Lee JY, Kim SW, Kang HJ, Kim SY, Bae KY, Kim JM, et al. Relationship between problematic internet Se and post-traumatic stress disorder among students following the sewol ferry disaster in South Korea. Psychiatry Investig. (2017) 14:871-5. doi: 10.4306/pi.2017.14.6.871

45. Mitchell JD, Brown ES, Rush AJ. Comorbid disorders in patients with bipolar disorder and concomitant substance dependence. J Affect Disord. (2007) 102:281-7. doi: 10.1016/j.jad.2007.01.005

46. First MB, Williams JBW, Karg RS, Spitzer RL. Structured Clinical Interview for DSM-5 Disorders, Clinician Version (SCID-5-CV). Arlington, VA: American Psychiatric Association (2016).

47. Dell'Osso L, Gesi C, Massimetti E, Cremone IM, Barbuti M, Maccariello G, et al. Adult Autism Subthreshold Spectrum (AdAS Spectrum): validation of a questionnaire investigating subthreshold autism spectrum. Compr Psychiatry. (2017) 73:61-83. doi: 10.1016/j.comppsych.2016.11.001

48. Dell'Osso L, Shear MK, Carmassi C, Rucci P, Maser JD, Frank E, et al. Validity and reliability of the Structured Clinical Interview for the Trauma and Loss Spectrum (SCI-TALS). Clin Pract Epidemiol Ment Health. (2008) 4:2. doi: 10.1186/1745-0179-4-2

49. Dell'Osso L, Carmassi C, Rucci P, Conversano C, Shear MK, Calugi S, et al. A multidimensional spectrum approach to post-traumatic stress disorder: comparison between the Structured Clinical Interview for Trauma and Loss Spectrum (SCI-TALS) and the Self-Report instrument (TALSSR). Compr Psychiatry. (2009) 50:485-90. doi: 10.1016/j.comppsych.2008. 11.006

50. Carmassi C, Corsi M, Bertelloni CA, Carpita B, Gesi C, Pedrinelli V, et al. Mothers and fathers of children with epilepsy: gender differences in posttraumatic stress symptoms and correlations with mood spectrum symptoms. Neuropsychiatr Dis Treat. (2018) 14:1371-9. doi: 10.2147/NDT.S158249

51. Jacobsen LK, Southwick SM, Kosten TR. Substance use disorders in patients with posttraumatic stress disorder: a review of the literature. Am J Psychiatry. (2001) 158:1184-90. doi: 10.1176/appi.ajp.158.8.1184

52. Grubbs JB, Chapman H, Milner L, Gutierrez IA, Bradley DF. Examining links between posttraumatic stress and gambling motives: the role of positive gambling expectancies. Psychol Addict Behav. (2018) 32:821-31. doi: $10.1037 / \mathrm{adb} 0000399$

53. Hernandez JM, Cordova MJ, Ruzek J, Reiser R, Gwizdowski IS, Suppes $\mathrm{T}$, et al. Presentation and prevalence of PTSD in a bipolar disorder population: a STEP-BD examination. J Affect Disord. (2013) 150:450-5. doi: 10.1016/j.jad.2013.04.038
54. Cerimele JM, Bauer AM, Fortney JC, Bauer MS. Patients with co-occurring bipolar disorder and posttraumatic stress disorder: a rapid review of the literature. J Clin Psychiatry. (2017) 78:e506-14. doi: 10.4088/JCP.16r10897

55. Carmassi C, Bertelloni CA, Dell'Oste V, Foghi C, Diadema E, Cordone A, et al. Post-traumatic stress burden in a sample of hospitalized patients with Bipolar Disorder: which impact on clinical correlates and suicidal risk?. J Affect Disord. (2020) 262:267-72. doi: 10.1016/j.jad.2019.10.044

56. Dell'osso L, Carmassi C, Rucci P, Ciapparelli A, Paggini R, Ramacciotti CE, et al. Lifetime subthreshold mania is related to suicidality in posttraumatic stress disorder. CNS Spectr. (2009) 14:262-6. doi: 10.1017/s1092852900025426

57. Dell'Osso L, Da Pozzo E, Carmassi C, Trincavelli ML, Ciapparelli A, Martini C. Lifetime manic-hypomanic symptoms in post-traumatic stress disorder: relationship with the $18 \mathrm{kDa}$ mitochondrial translocator protein density. Psychiatry Res. (2010) 177:139-43. doi: 10.1016/j.psychres.2008.07.019

58. Steinbuchel PH, Wilens TE, Adamson JJ, Sgambati S. Posttraumatic stress disorder and substance use disorder in adolescent bipolar disorder. Bipolar Disord. (2009) 11:198-204. doi: 10.1111/j.1399-5618.2008.00652.x

59. Schell TL, Marshall GN, Jaycox LH. All symptoms are not created equal: the prominent role of hyperarousal in the natural course of posttraumatic psychological distress. J Abnorm Psychol. (2004) 113:189-97. doi: 10.1037/0021-843X.113.2.189

60. Barrett EL, Teesson M, Mills KL. Associations between substance use, post-traumatic stress disorder and the perpetration of violence: a longitudinal investigation. Addict Behav. (2014) 39:1075-80. doi: 10.1016/j.addbeh.2014.03.003

61. Smith KZ, Smith PH, Cercone SA, Mckee SA, Homish GG. Past year non medical opioid use and abuse and PTSD diagnosis: interactions with sex and association with symptom clusters. Addict Behav. (2016) 58:167-74. doi: 10.1016/j.addbeh.2016.02.019

62. Buckner JD, Jeffries ER, Crosby RD, Zvolensky MJ, Cavanaugh CE, Wonderlich SA. The impact of PTSD clusters on cannabis use in a racially diverse trauma-exposed sample: An analysis from ecological momentary assessment. Am J Drug Alcohol Abuse. (2018) 44:1-1. doi: 10.1080/00952990.2018.1430149

63. Dworkin ER, Wanklyn S, Stasiewicz PR, Coffey SF. PTSD symptom presentation among people with alcohol and drug use disorder: comparison by substance of abuse. Addict Behav. (2018) 76:188-94. doi: 10.1016/j.addbeh.2017.08.019

64. Yau YH, Potenza MN. Gambling disorder and other behavioral addictions: recognition and treatment. Harv Rev Psychiatry. (2015) 23:134-46. doi: 10.1097/HRP.0000000000000051

65. Carlo Di F, Pettorruso M, Alessi MC, Picutti E, Collevecchio R, Migliara $\mathrm{G}$, et al. Characterizing the building blocks of Problematic Use of the Internet (PUI): The role of obsessional impulses and impulsivity traits among Italian young adults. Compr Psychiatry. (2021) 106:152225. doi: 10.1016/j.comppsych.2021.152225

66. Provencher MD, Hawke LD, Thienot E. Psychotherapies for comorbid anxiety in bipolar spectrum disorders. J Affect Disord. (2011) 133:371-80. doi: 10.1016/j.jad.2010.10.040

67. Stratford HJ, Cooper MJ, Simplicio Di M, Blackwell SE, Holmes EA. Psychological therapy for anxiety in bipolar spectrum disorders: a systematic review. Clin Psychol Rev. (2015) 35:19-34. doi: 10.1016/j.cpr.2014.11.002

68. Mauritz MW, Van Gaal BGI, Jongedijk RA, Schoonhoven L, Nijhuis-van der Sanden MWG, Goossens PJJ. Narrative exposure therapy for posttraumatic stress disorder associated with repeated interpersonal treuma in patients with severe mental illness: a mixed methods design. Eur J Psychotraumatol. (2016) 7:1. doi: 10.3402/ejpt.v7.32473

Conflict of Interest: The authors declare that the research was conducted in the absence of any commercial or financial relationships that could be construed as a potential conflict of interest.

Copyright (c) 2021 Carmassi, Bertelloni, Cordone, Dell'Oste, Pedrinelli, Barberi, Massimetti, Bui and Dell'Osso. This is an open-access article distributed under the terms of the Creative Commons Attribution License (CC BY). The use, distribution or reproduction in other forums is permitted, provided the original author(s) and the copyright owner(s) are credited and that the original publication in this journal is cited, in accordance with accepted academic practice. No use, distribution or reproduction is permitted which does not comply with these terms. 